\title{
Strategi Pemasaran Islami dalam Meningkatkan Penjualan Produk dengan Matrik BCG dan SWOT Analisis
}

\section{Islamic Marketing Strategy in Increasing Product Sales with BCG Matrix and SWOT Analysis}

\author{
Ekie Gilang Permata ${ }^{1}$, Suherman $^{2}$, Rahmi Aini ${ }^{3}$ \\ Jurusan Teknik Industri, Fakultas Sains dan Teknologi, UIN Sultan Syarif Kasim Riau \\ Jl. HR. Soebrantas No. 155 Simpang Baru, Panam, Pekanbaru, 28293 \\ E-mail: ekiegp@yahoo.com; suher_aje@yahoo.co.id; rahmiaini10@gmail.com
}

\begin{abstract}
ABSTRAK
Startegi Pemasaran dapat menentukan tujuan perusahaan dalam mengambil kebijakan dan aturan yang dapat memberikan arahan sebagai tanggapan perusahaan dalam menghadapi lingkungan dan keadaan pesaing yang selalu berubah. Studi kasus ini pada perusahaan produksi berbagai macam hijab. perusahaan ini memiliki penjualan yang fluktuasi karena pemesanan konsumen yang tidak menentu setiap tahunnya dan munculnya pesaing dengan jenis hijab yang sama. Melihat banyaknya pesaing maka perusahaan ini harus mengetahui kondisi perusahaan dengan perhitungan matrik BCG dan mengetahui faktor eksternal (EFE) dfaktor internal (IFE) untuk menghadapi persaingan dengan hasil analisis SWOT. Hasilnya perusahan ini berada pada posisi Qustion Mark pada matrik BCG dengan tingkat pertumbuhan pasar $21 \%$ dan pangsa pasar relatif 0,69 . Pada hasil perhitungan matrik IE perusahaan ini berada pada kuadran II yaitu perusahaan harus melakukan strategi tumbuh dan membangun. Hasil analisis SWOT dilakukan berdasarkan salah satu sifat nabi Muhammad adalah tabligh (menyampaikan).
\end{abstract}

Kata Kunci: Strategi Pemasaran, Matrik BCG, analisis SWOT

\begin{abstract}
Marketing strategies can determine the company's goals in taking policies and rules that can provide direction in response to the company's response to the ever-changing environment and competitor circumstances. This case study is on a company producing various kinds of hijab. This company has fluctuating sales due to erratic consumer orders every year and the emergence of competitors with the same type of hijab. Seeing the large number of competitors, this company must know the condition of the company by calculating the BCG matrix and knowing the external factors (EFE) and internal factors (IFE) to face competition with the results of the SWOT analysis. As a result, this company is in the Question Mark position in the BCG matrix with a market growth rate of $21 \%$ and a relative market share of 0.69 . In the results of the calculation of the IE matrix, the company is in quadrant II, namely the company must carry out a growth and building strategy. The results of the SWOT analysis were carried out based on one of the characteristics of the prophet Muhammad, namely tabligh (conveying).
\end{abstract}

Keywords: Marketing Strategy, BCG Matrix, SWOT analysis

\section{Pendahuluan}

Semakin pesatnya perkembangan fashion dibidang hijab dengan model yang berbagai macam dan model pada saat ini. Pada zaman dahulu hijab yang fungsinya menutup aurat sekarang sudah menjadi fashiongaya yang banyak diminati baik dikalangan orang dewasa bahkan anak kecil. Usaha kecil atau industri rumahan hingga perusahaanperusahaan besar sudah banyak memproduksi berbagai produk fashion seperti produk hijab atau kerudung dengan berbagai macam model, motif dan warna. Pada umumnya perusahaan masih banyak yang berpendapat keliru bahwa apabila penjualan produknya terus meningkat maka usaha tersebut dianggap tidak mempunyai permasalahan yang sifatnya strategis, padahal pada kenyataannya yang terjadi adalah para pesaing sudah siap untuk menyaingi usahanya (Peratiwi dan Subhan, 2017). Dilloka hijab merupakan salah satu usaha home 
industry yang bergerak di bidang produksi hijab. Dilloka hijab berdiri pada tahun 2015 yang terletak di Jalan Bakti Marpoyan Damai Pekanbaru. Hijab yang diproduksi adalah hijab dengan warna polos dan motif, pashmina dan khimar. Dilloka hijab merupakan UKM yang terbilang baru dan belum membuka toko nya sendiri, promosi yang dilakukan dengan bantuan media sosial dan membuka bazar di beberapa mall seperti Living World, Ciputra dan SKA.

Banyaknya pesaing usaha sejenis yang bergerak dibidang yang sama yaitu usaha rumahan dan shop online menunjukan tingkat persaingan semakin ketat, sehingga perusahaan harus pandai dalam mengelola usahanya dan mencari cara dan strategi untuk mendapatkan peluang dalam bersaing. Hal ini menyebabkan terjadinya fluktuasi dalam penjualan pada Dilloka hijab. Dilloka hijab:

Berikut adalah data penjualan hijab pada

Tabel 1. Penjualan hijab Dilloka

\begin{tabular}{|c|c|}
\hline TAHUN & DATA PENJUALAN \\
\hline 2015 & $\operatorname{Rp} 35.000 .000$ \\
\hline 2016 & $\operatorname{Rp} 33.000 .000$ \\
\hline 2017 & $\operatorname{Rp} 27.000 .000$ \\
\hline 2018 & $\operatorname{Rp} 42.000 .000$ \\
\hline 2019 & $\operatorname{Rp} 51.000 .000$ \\
\hline
\end{tabular}

Melihat banyaknya pesaing khususnya dibidang fashion hijab, maka industri rumahan Dilloka harus mengetahui kondisi perusahaan dalam pangsa pasar untuk menghadapi pesaing dengan perhitungan matrik BCG dan mengetahui faktorfaktor untuk menghadapi persaingan dengan hasil analisis SWOT. Analisis matrik BCG merupakan suatu strategi melakukan pengklasifikasian penyusunan perencanaan suatu usaha untuk potensi keuntungan perusahaan, kemudian dimasukan ke matriks Boston Consulting Group secara grafis akan menunjukan perbedaan antara berbagai divisi dalam posisi pangsa pasar relatif dan tingkat pertumbuhan pasar. Analisis SWOT digunakan untuk mengidentifikasi beberapa faktor secara sistematis untuk merumuskan strategi perusahaan.Analisis ini didasarkan dalam memaksimalkan kekuatan (Strengths) dan peluang (Opportunities), namun secara bersamaan dapat meminimalkan kelemahan (Weaknesses) dan ancaman (Threats).

\section{Metode Penelitian}

Strategi pemasaran adalah serangkaian tujuan dan sasaran perusahaan dalam mengambil kebijakan dan aturan yang dapat memberikan arahan kepada usaha-usaha pemasaran dari waktu ke waktu, pada masing-masing tingkatan dan acuan serta alokasinya, terutama sebagai tanggapan perusahaan dalam menghadapi lingkungan dan keadaan pesaing yang selalu berubah. (Agusrinal dan Diniaty, 2014)

Pemasaran islami adalah strategi bisnis yang harus melindungi seluruh aktivitas dalam sebuah perusahaan, meliputi seluruh proses, menciptakan, menawarkan, pertukaran nilai, dari seorang produsen, atau satu perusahaan, atau perorangan yang sesuai dengan ajaran islam (Kamaruddin,2017).

Analisis BCG merupakan metode yang digunakan dalam menyusun suatu perencanaan unit bisinis strategi dengan melakukan pengklasifikasian terhadap potensi keuntungan perusahaan, kemudian dimasukan ke matriks Boston Consulting Group secara grafis menunjukan perbedaan antara berbagai divisi dalam posisi pangsa pasar relatif dan tingkat pertumbuhan pasar (Peratiwi dan Subhan, 2017).

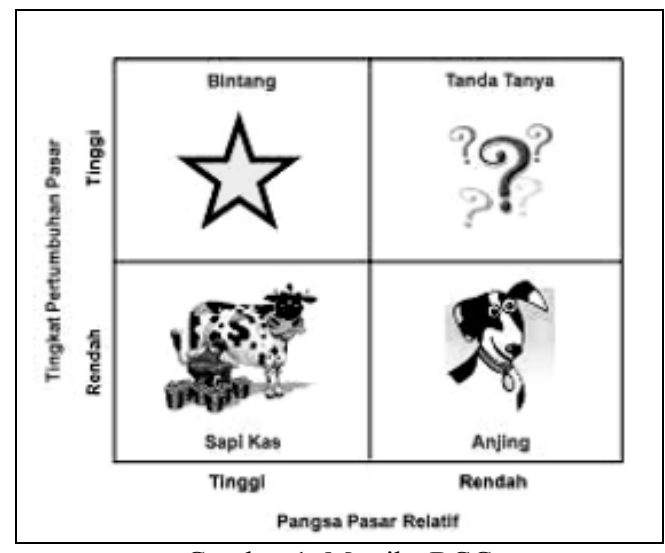

Gambar 1. Matriks BCG

(Sumber: Peratiwi dan Subhan, 2017)

Dalam matriks Boston Consulting Group (BCG) terdapat beberapa konsep yang harus dipahami, yaitu:

1. Tingkat Pertumbuhan Pasar (Market Growth

Rate)

Pertumbuhan pasar diwakili oleh sumbu vertikal.Pertumbuhan pasar adalah proyeksi tingkat penjualan untuk pasar.

$$
\mathrm{TPP}=\frac{\mathrm{VPN}-\mathrm{VPN}-1}{\mathrm{VP} \mathrm{N}-1} \times 100 \%
$$

Keterangan:

TPP = Tingkat pertumbuhan pasar

VP N = Volume penjualan perusahaan tahun terakhir

VP N-1= Volume penjualan perusahaan tahun sebelumnya.

2. Pangsa Pasar Relatif (Relative Market Share)

Pangsa pasar relatif adalah adalah bagian penjualanindustri total sebuah perusahaan di sebuah 
pasar tertentu. Pangsa pasar relatif diwakili oleh sumbu horisontal.

Keterangan:

$$
\mathrm{PPR}=\frac{\mathrm{VPN}}{\mathrm{VPPN}}
$$

$$
\begin{array}{ll}
\text { PPR } & =\text { Pangsa pasar relatif } \\
\text { VP N } & =\text { Volume penjualan tahun terakhir } \\
\text { VPP N } & =\text { Volume penjualan tahun terakhir } \\
& \text { pesaing }
\end{array}
$$

Matriks IE (Internal Eksternal) bermanfaat untuk memposisikan perusahaan ke dalam matriks yang terdiri dari 9 sel. Matriks IE terdiri dari dua dimensi, yaitu total skor matriks IFE pada sumbu X dan Matriks EFE pada sumbu Y. Matriks ini dikelompokkan menjadi tiga strategi utama yaitu (Setyorini, 2016):

a. Grow and Build (Tumbuh dan Membangun) Berada dalam sel I, II atau IV. Strategi yang cocok adalah intensif (meningkatkan penjualan pasar, pengembangan pasar, dan pengembanganproduk) atau integrasi (integrasi ke belakang, integrasi ke depan, dan integrasi horizontal).

b. Hold and Maintain (Pertahankan dan Pelihara)

Mencangkup sel III, V, atau sel VII. Strategi umum yang dipakai adalah penetrasi pasar atau meningkatkan penjualan pasar, pengembangan produk dan pengembangan pasar.

c. Harvest and Devest (Panen atau Divestasi) Mencangkup sel VI, VIII, atau IX. Strategi yang dipakai adalah divestasi atau penguran beberapa jenis produk, dan strategi likuidasi atau pembubaran perusahaan.

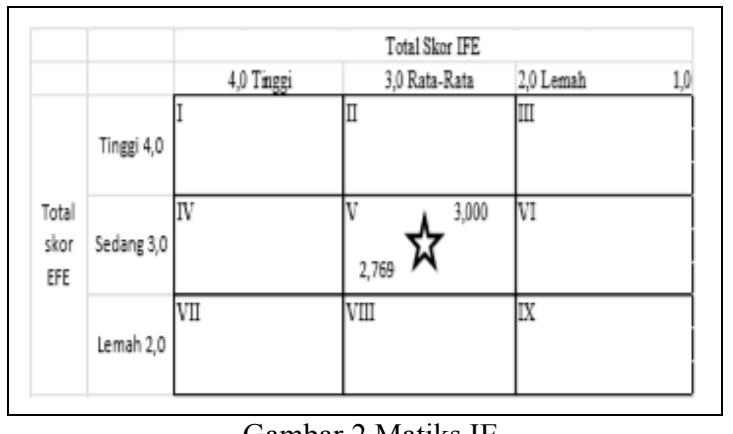

(Sumber: Peratiwi dan Subhan, 2017)

Menurut Rangkuti (1997), Analisis SWOT adalah sebuah metode perencanaan strategis yang digunakan untuk mengevaluasi kekuatan (strengths), kelemahan (weakness), peluang (opportunities), dan ancaman (threats).

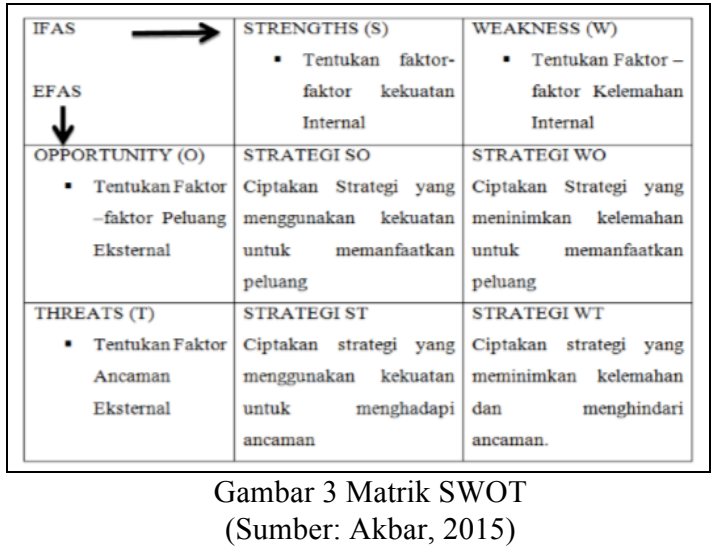

\section{Hasil dan Pembahasan}

\section{Pengolahan Matrik BCG}

Data yang digunakan untuk matrik BCG (Boston Consulting Group) yaitu data volume penjualan Dilloka Hijab dan total volume penjualan pesaing, selanjunya untuk menentukan letak perusahaan pada kuadran matrik BCG dengan menghitung tingkat pertumbuhan pasar dan pangsa pasar relatif perusahaan.

1. Perhitungan Tingkat Pertumbuhan Pasar (Market Grow Rate)

Tingkat pertumbuhan pasar dapat dihitung dengan cara:

$$
\begin{aligned}
\mathrm{TPP} & =\frac{\mathrm{VP} N-\mathrm{VPN}-1}{\text { VP N-1 }} \times 100 \% \\
& =\frac{\text { VP } 2019-\mathrm{VP} 2018}{\mathrm{VP} 2018} \times 100 \% \\
& =\frac{51.000 .000-42.000 .000}{42.000 .000} \times 100 \% \\
& =21 \%
\end{aligned}
$$

Hasil dari perhitungan tingkat pertumbuhanpasar yang didapatkan perusahaan Dilloka Hijab adalah $21 \%$.Dalam matrik BCG Dilloka Hijab memiliki tingkat pertumbuhan pasar yang tinggi, terlihat dari kenaikan penjualan dari tahun 2018 ke 2019.

2. Pangsa Pasar Relatif (Relative Market Share)

Pangsa Pasar Relatif merupakan proporsi kemampuan perusahaan terhadap penjualan keseluruhan pesaing dan juga perusahaan itu sendiri. Pangsa pasar relatif dapat dihitung menggunakan rumus sebagai berikut:

$$
\begin{aligned}
\mathrm{PPR} & =\frac{\mathrm{VPN}}{\mathrm{VPPN}} \\
& =\frac{51.000 .00 \mathrm{C}}{73.000 .00 \mathrm{C}} \\
& =0,69
\end{aligned}
$$

Hasil perhitungan tingkat Pangsa Pasar Relatif Dilloka Hijab dibandingkan dengan perusahaan pesaing sebesar 0,69 menunjukan 
bahwa Dilloka Hijab memiliki pangsa pasar relatif lebih rendah dibandingkan dengan perusahaan pesaing karna nilai pangsa pasar relatif lebih kecil dari pada 1 .

Analisis yang dilakukan terhadap data menggunakan matrik BCG dengan membandingkan tingkat pertumbuhan pasar dan pangsa pasar relatif, maka posisi Dilloka Hijab dapat dilihat pada gambar berikut:

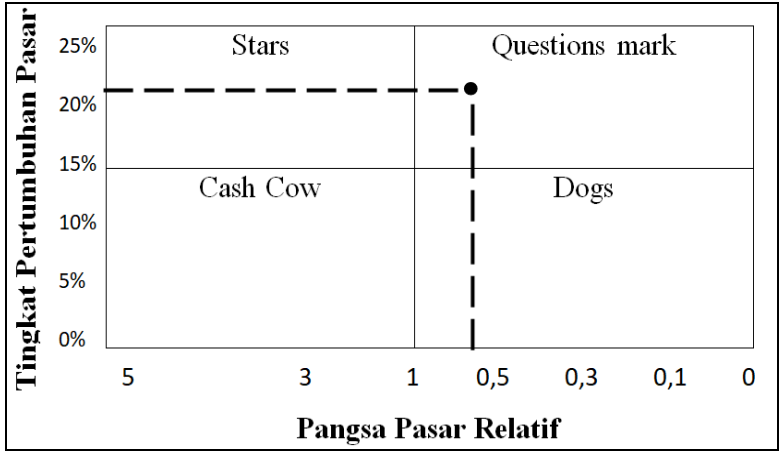

Gambar 4.1. Grafik Matrik BCG

(Sumber: Pengolahan Data, 2020)

Hasil perhitungan matrik BCG dapat dilihat bahwa Dilloka Hijab dengan pesaing berada di posisi Question Mark, dengan perhitungan tingkat pertumbuhan pasar $21 \%$ dan perhitungan pangsa pasar relatif 0,69 yang berarti bahwa posisi perusahaan berada dalam kondisi menghadapi pangsa pasar yang rendah dan terjadi kondisi pertumbuhan yang tinggi, sehingga seolah-olah bahwa cash flow lemah. Pada posisi ini perusahaan harus menjalankan strategi seperti mengembangkan produk baru yang nantinya akan diproduksi agar bisa mengikuti kondisi keinginan pasar yang tinggi.

\section{Analisis Lingkungan Internal Perusahaan}

Lingkungan internal perusahaan dilakukan untuk mengetahui kekuatan dan kelemahan perusahaan.Faktor-faktor internal perusahaan yang digunakan pada penelitian terdiri dari manajemen, pemasaran, keuangan atau akuntansi, penelitian dan pengembangan dan sistem informasi.

1. Manajemen

Perusahaan Dilloka Hijab dalam melakukan proses produksi antara pemilik dan karyawan saling bekerja sama dalam memproduksi hijab yang ingin dipasarkan seperti bahan yang digunakan dan model yang harus diproduksi. Setiap karyawan melakukan tugas nya sesuai dengan jabatan nya. Serta pemilik melakukan kontrol terhadap tugas karyawan dan hijab yang diproduksi dan mengontrol setiap outlet yang dibuka.

2. Pemasaran

Pasar sasaran dari Dilloka Hijab adalah semua kalangan umur wanita, dengan sistem pemasaran yang dilakukan menggunakan media sosial.

a. Produk

Produk yang dihasilkan dari Dilloka Hijab memiliki model yang hampir sama dengan perusahaan hijab lainnya. Model hijab yang diproduksi Dilloka Hijab yaitu, hijab dengan warna polos dan motif, pashmina dan khimar.

b. Harga

Harga jilbab yang ditawarkan oleh Dilloka Hijab cukup terjangkau dan dapat bersaing di pasaran. Produk hijab polos dengan ukuran standar dengan harga $\mathrm{Rp} 40.000$, hijab motif dengan harga Rp 45.000, hijab pashmina dengan harga Rp 45.000 dan khimar dengan harga Rp 60.000.

c. Tempat

Dilloka Hijab belum memiliki toko nya sendiri, perusahaan melakukan bazar di beberapa mall seperti Living World, mall Ciputra dan mall SKA. Outlet Dilloka Hijab terletak berdekatan dengan perusahaan hijab pesaing.

d. Promosi

Promosi yang dilakukan Dilloka Hijab dengan menggunakan media sosial khususnya instagram.

3. Keuangan atau akuntansi

Sumber keuangan yang digunakan mulai dari awal usaha dari modal pribadi.Karena minimnya modal yang dimiliki sehingga usaha sulit dikembangkan.Dilloka Hijab hanya melakukan catatan-catatan dibuku hanya mengetahui uang masuk atau modal dan jumlah produksi dan produk yang terjual perbulannya.

4. Penelitian dan Pengembangan

Pemilik Dilloka hijab melakukan penelitian terhadap bahan dan model hijab yang disenangi oleh konsumen sehingga pemilik mengetahui bahan yang disenangi dan dilakukan pengembangan terhadap bahan dan model tersebut.

5. Sistem Informasi Manajemen

Informasi yang selama ini digunakan Dilloka Hijab terhadap karyawannya menggunakan telepon seluler berupa grup pada Whatssapp.

\section{Analisis Lingkungan Eksternal Perusahaan}

Lingkungan eksternal perusahaan dilakukan untuk mengarah pada faktor peluang dan ancaman yang harus dihindari perusahaan. Lingkungan faktor eksternal perusahaan terbagi menjadi lingkungan makro dan lingkungan mikro.

1. Lingkungan Makro

a. Faktor Demografi

Bertambahnya jumlah penduduk di Indonesia dan populasi perempuan yang lebih banyak dari populasi laki-laki, merupakan satu kekuatan yang dimiliki perusahaan. Dengan populasi perempuan yang bertambah dan negara Indonesia merupakan negara mayoritas Islam sehingga akan berdampak positif pada peningkatan penjualan hijab dan 
merupakan peluang terhadap perkembangan usaha Dilloka Hijab.

b. Faktor Ekonomi

Kondisi perekonomian Indonesia yang masih belum stabil dapat memberikan dampak bagi perkembangan usaha di Indonesia. Hal ini dapat dilihat dengan terus naiknya harga bahan bakar minyak dan gas yang berpengaruh terhadap kenaikan harga barang-barang lainnya tidak terkecuali bahan baku dan pendukung bahan Dilloka Hijab.

c. Faktor Sosial

Perkembangan zaman dan pertumbuhan jumlah penduduk telah merubah kehidupan sosial dan budaya masyarakat, dan pola hidup masyarakat. Jika melihat pola hidup masyarakat saat ini yang cenderung lebih modern hal ini dapat menjadi suatu peluang, karena masyarakat ingin selalu memiliki produk hijab terbaru sesuai dengan perkembangan di masyarakat. Sifat manusia yang tidak pernah puas memaksakan manusia akan selalu membeli produk hijab terbaru agar tidak merasa tersaingi dengan masyarakat lain.

\section{d. Faktor Teknologi}

Kemajuan teknologi komunikasi telah terbukti memperlancar transaksi jual beli produk dari produsen ke konsumen. Selain itu Dilloka Hijab ini dapat memanfaatkan perkembangan teknologi internet untuk menjual atau mempromosikan produknya secara online. Hal ini bisa dijadikan peluang oleh perusahaan Dilloka Hijab.

e. Faktor Politik

Perusahaan perlu mengetahui secara terus menerus mengenai situasi politik, peraturanperaturan dan kebijakan-kebijakan pemerintah baik pemerintah pusat maupun pemerintah daerah, terutama kebijakan mengenai UMKM dapat mempengaruhi perkembangan usaha Dilloka Hijab. Peraturan yang dibuat dapat mempengaruhi perusahaan dalam hal memudahkan perusahaan atau mempersulit perusahaan untuk berkembang sehingga dapat menjadi peluang atau ancaman. Keadaan politik yang tidak stabil akan menyebabkan ancaman pada nilai tukar rupiah yang tidak stabil dan berdampak juga pada penurunan nilai investasi, penanaman modal dan nilai daya beli masyarakat di dalam negeri.

\section{Lingkungan Mikro}

a. Pemasok

Bahan baku yang dibutuhkan adalah berbagai macam bahan kain. Bahan-bahan diperoleh oleh pemilik perusahaan dari pasar yang khusus menjual berbagai bahan kain.

b. Pelanggan

Pelanggan yang dimiliki Dilloka Hijab yaitu pasar konsumen yang tidak tetap, sehingga pelanggan beralih pada pesaing yang juga menjual hijab.

\section{c. Pesaing}

Muncul nya pesaing-pesaing baru yang menjual hijab baik yang memiliki hijab dengan model yang sama maupun pesaing yang menjual hijab dengan model baru.

3. Lingkungan Industri

a. Ancaman Pendatang Baru

Munculnya pendatang baru dalam industri produksi hijab dapat menjadi suatu ancaman bagi Dilloka Hijab terhadap pangsa pasar. Meskipun pendatang baru tersebut mempunyai skala yang lebih kecil, namun hal ini secara tidak langsung akan menjadi pesaing yang berskala besar apabila tidak dilakukan antisipasi terhadap pendatang baru. Pendatang baru akan melakukan produksi dengan model dan bahan lebih inovatif untuk menarik konsumen.

b. Ancaman Produk Subsitusi

Ancaman produk substitusi dapat terjadi jika konsumen dihadapkan pada harga yang lebih murah dan kualitas yang sama atau lebih baik dibandingkan dengan produk perusahaan tersebut. Dilloka hijab dipasarkan pada tempat yang banyak menjual hijab, maka konsumen akan lebih memilih dalam membeli produk hijab.

c.Persaingan dari perusahaan sejenis dalam industri

Persaingan dalam industri akan mempengaruhi kebijakan dan kinerja dari industri. Persaingan antar perusahaan produksi hijab sangat banyak bahkan dengan model dan bahan hijab yang sama. Sehingga Dilloka Hijab harus melakukan pengembangan produk secara terus menerus agar dapat bersaing dengan perusahaan lain.

\section{Matrik IFE (Internal Factor Evaluation)}

Analisis matrik IFE merupakan hasil dari identifikasi faktor internal berupa kekuatan (Strengths) dan kelemahan (Weakness) yang berpengaruh terhadap Dilloka Hijab.

Berdasarkan hasil perhitungan dengan menggunakan matrik IFE diperoleh total skor yang dimiliki Dilloka Hijab sebesar 2,828. Skor bobot total berada pada posisi internal rata-rata mengindikasikan bahwa posisi internal perusahaan dalam mengatasi kelemahan yang ada berada pada posisi yang rata-rata dengan kekuatan yang dimilikinya.

Hasil kekuatan utama perusahaan adalah promosi dilakukan secara aktif di media sosial dengan skor 0,4536, karena perusahaan Dilloka hijab sangat mengandalkan media sosial dalam menjual produknya pada konsumen.

Adapun kelemahan utama yang dimiliki oleh Dilloka Hijab adalah variasi model hampir sama dengan pesaing dengan skor 0,1248 . Hal ini menyebabkan produk Dilloka Hijab kesulitan bersaing dengan produk lain. 


\section{Matrik EFE (Eksternal Factor Evaluation)}

Analisis matrik EFE merupakan hasil dari identifikasi faktor eksternal berupa peluang (Opportunities) dan ancaman (Treathts) yang berpengaruh terhadap Dilloka Hijab.

Berdasarkan hasil perhitungan dengan menggunakan matrik EFE diperoleh total skor yang dimiliki oleh Dilloka Hijab sebesar 3,0612. Hasil skor bobot total menyatakan perusahaan mampu merespon dengan baik faktor eksternal dengan memanfaatkan peluang yang ada untuk mengatasi ancaman.

Peluang utama yang dimiliki oleh perusahaan adalah perkembangan dunia internet atau promosi secara online dengan skor 0,5472 . Pada dunia teknologi saat ini semakin berkembang dan masyarakat lebih banyak menggunakan internet sehingga promosi secara online dapat menjadi peluang dalam mempromosikan produk kepada konsumen.

Ancaman utama dari Dilloka Hijab ini adalah naiknya harga bahan baku dan pendukung dengan skor 0,408. Harga bahan baku dan pendukung yang selalu mengalami fluktuasi dapat menjadi ancaman bagi perusahaan.

\section{Matriks IE (Internal-Eksternal)}

Berdasarkan hasil yang diperoleh dari matrik IFE dan matrik EFE maka dapat disusun selanjutnya dalam matrik internal-eksternal atau matrik IE. Matrik IE digunakan untuk menganalisis posisi perusahaan secara lebih detail dan melihat strategi apa yang tepat untuk diterapkan oleh perusahaan. Hasil dari penilaian dari matrik IE untuk Dilloka Hijab adalah nilai rata-rata IFE sebesar 2,828 dan rata-rata EFE sebesar 3,0612 menunjukkan posisi Dilloka Hijab berada pada kuadran II. Pada posisi ini strategi yang tepat untuk digunakan adalah strategi tumbuh dan membangun.

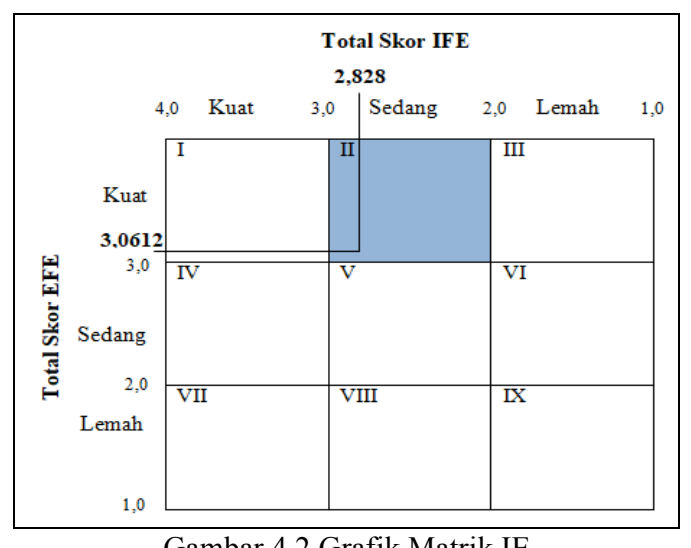

Gambar 4.2 Grafik Matrik IE

(Sumber: Pengolahan Data, 2020)

\section{Analisis Matrik SWOT}

Berdasarkan analisis faktor internal dan eksternal perusahaan menghasilkan beberapa strategi alternatif yang diperoleh dari variabelvariabel sesuai dengan posisi perusahaan, maka alternatif-alternatif strategi yang didapat adalah:

1. Strategi S-O (Strenghts-Opportunities)

Strategi ini adalah untuk menciptakan strategi menggunakan kekuatan untuk memanfaatkan peluang. Strategi yang dapat digunakan yaitu pertama, mempertahankan dan meningkatkan kualitas dan harga untuk meningkatkan penjualan, kedua untuk memberikan potongan harga pada konsumen yang membeli dalam jumlah besar, ketiga untuk menjalin kerja sama yang baik kepada karyawan maupun distributor dan keempat untuk melakukan pelayanan yang komunikatif dengan konsumen. Strategi yang ketiga dan keempat merupakan strategi yang berhubungan dengan sifat nabi Muhammad yaitu tabligh (komunikatif).Dalam melakukan usaha diperlukan sifat tabligh (komunikatif) dalam melakukan hubungan baik kepada karyawan, distributor maupun konsumen agar usaha yang dilakukan dapat berlanjut dan tidak terjadi kesalah pahaman yang dapat merugikan salah satu baik karyawan, distibutor dan konsumen.

\section{Strategi S-T (Strenghts-Treathts)}

Strategi ini adalah untuk menciptakan strategi menggunakan kekuatan untuk menghadapi ancaman. Strategi yang dapat digunakan yaitu dengan menciptakan produk dengan model yang baru dengan tetap memperhatikan kualitas dan harga yang terjangkau untuk dapat bersaing dengan produk sejenis maupun pesaing baru dan melakukan promosi secara continue sehingga menarik konsumen dengan berdasarkan pada sifat nabi Muhammad SAW salah satunya tabligh (komunikatif) dengan melakukan promosi menyampaikan keunggulan-keunggulan produk dengan menarik dan tepat sasaran tanpa meninggalkan kejujuran dan kebenaran.

\section{Strategi W-O (Weaknesses-Opportunities)}

Strategi ini diterapkan untuk menciptakan strategi dengan meminimalkan kelemahan untuk memanfaatkan peluang. Strategi yang dapat digunakan yaitu pertama melakukan pengembangan produk untuk menarik konsumen, kedua dengan memperkuat modal melalui kerja sama dengan investor, dan ketiga memperluas area pemasaran dengan bekerja sama dengan agen.

\section{Strategi W-T (Weaknesses-Treathts)}

Strategi ini digunakan untuk menciptakan strategi dengan meminimalkan kelemahan dan menghindari ancaman. Strategi yang dapat dilakukan yaitu dengan menjalin dan mengembangkan kerja sama dengan pihak yang menyediakan modal dan bahan baku untuk meningkatkan kapasitas produksi. 


\section{Kesimpulan}

Hasil pengolahan menggunakan perhitungan matriks BCG dalam menentukan letak perusahaan pada kuadran matrik BCG dengan menghitung tingkat pertumbuhan pasar dan pangsa pasar relatif perusahaan. Hasil perhitungan matrik BCG dapat dilihat bahwa Dilloka Hijab dengan pesaing berada di posisi Question Mark, dengan perhitungan tingkat pertumbuhan pasar $21 \%$ dan perhitungan pangsa pasar relatif 0,69 yang berarti bahwa posisi perusahaan berada dalam kondisi menghadapi pangsa pasar yang rendah dan terjadi kondisi pertumbuhan yang tinggi.

Faktor internal dilakukan untuk mengetahui kekuatan dan kelemahan perusahaan. Kekuatan perusahaan yaitu, perencanan produksi dilakukan secara bersama antara karyawan dan pemimpin, Setiap jabatan melakukan sesuai dengan tugasnya, pemilik mengontrol setiap outlet dan proses produksi secara rutin, harga terjangkau dapat bersaing dipasar, promosi dilakukan secara aktif dimedia sosial, modal sendiri, melakukan pengembangan produk dan menggunakan media sosial. Sedangkan kelemahan perusahaan yaitu, variasi model hampir sama dengan pesaing, belum memiliki toko sendiri dan minimnya modal yang dimiliki.

Faktor eksternal merupakan hasil dari identifikasi faktor eksternal berupa peluang dan ancaman perusahaan. Peluang perusahaan yaitu, bertambahnya populasi penduduk dengan mayoritas islam, gaya hidup masyarakat yang tidak pernah puas dan tidak ingin ketinggalan zaman, perkembangan dunia internet atau promosi secara online dan ketersediaan bahan baku yang mudah didapat. Sedangkan ancaman perusahaan yaitu, naiknya harga bahan baku dan pendukung, fluktuasi nilai tukar uang, beralihnya pelanggan pada pesaing sejenis, masuknya pesaing baru yang tidak sejenis, banyaknya produk substitusi dan perusahaan lain dengan produk yang lebih inovatif. Maka dapat disusun selanjutnya dalam matrik internal-eksternal atau matrik IE. Matrik IE digunakan untuk menganalisis posisi perusahaan secara lebih detail dan melihat strategi apa yang tepat untuk diterapkan oleh perusahaan. Hasil dari penilaian dari matrik IE untuk Dilloka Hijab adalah nilai rata-rata IFE sebesar 2,828 dan rata-rata EFE sebesar 3,0612 menunjukkan posisi Dilloka Hijab berada pada kuadran II. Pada posisi ini strategi yang tepat untuk digunakan adalah strategi tumbuh dan membangun.

Usulan strategi perusahaan secara islami dari hasil metode yang digunakan berdasarkan sifat nabi Muhammad SAW yaitu Tabliq (komunikatif) adalah:

\section{a. Strategi S-O (Strenghts-Opportunities)}

Mempertahankan dan meningkatkan kualitas dan harga untuk meningkatkan penjualan, memberikan potongan harga pada konsumen yang membeli dalam jumlah besar, menjalin kerja sama yang baik kepada karyawan maupun distributor dan melakukan pelayanan yang komunikatif dengan konsumen. Strategi yang ketiga dan keempat merupakan strategi yang berhubungan dengan sifat nabi Muhammad yaitu tabligh (komunikatif).Dalam melakukan usaha diperlukan sifat tabligh (komunikatif) dalam melakukan hubungan baik kepada karyawan, distributor maupun konsumen agar usaha yang dilakukan dapat berlanjut dan tidak terjadi kesalah pahaman yang dapat merugikan salah satu baik karyawan, distibutor dan konsumen. b. Strategi S-T (Strenghts-Treathts)

Menciptakan produk dengan model yang baru dengan tetap memperhatikan kualitas dan harga yang terjangkau untuk dapat bersaing dengan produk sejenis maupun pesaing baru dan melakukan promosi secara continue sehingga menarik konsumen dengan berdasarkan pada sifat nabi Muhammad SAW salah satunya tabligh (komunikatif) dengan melakukan promosi menyampaikan keunggulan-keunggulan produk dengan menarik dan tepat sasaran tanpa meninggalkan kejujuran dan kebenaran.

\section{Daftar Pustaka}

Agusrinal dan Diniaty, D. (2014). Perancangan Strategi Pemasaran pada Produk Anyaman Pandan. Jurnal Sains, Teknologi dan Industri Vol. 11 No. 2.

Akbar, M. S. Muhammad, K. dan Ria, A. (2015). Analisa Strategi Pemasaran terhadap Performance Kerja dengan Menggunakan Metode Analisis SWOT (Studi Kasus : Pt. Dk). RATIH Vol. 1 Edisi 1.

Kamaruddin. (2017). Strategi Pemasaran terhadap Peningkatan Volume Penjualan Gas Elpiji Perspektif Ekonomi Islam. LAA MAISYIR Vol. 4 No. 1.

Rangkuti, F. (1997). Analisis SWOT: Teknik Membedah Kasus Bisnis. Jakarta: Kompas Gramedia.

Setyorini, H. Mas'ud, E. dan Imam, S. (2016). Analisis Strategi Pemasaran Menggunakan Matriks SWOT dan QSPM (Studi Kasus: Restoran WS Soekarno Hatta Malang). Industria: Jurnal Teknologi dan Manajemen AgroindustriVol. 5 No. 1.

Subhan, P dan Peratiwi, M. (2017). Analisis Strategi Pemasaran Produk dengan Metode Analisis Matrik BCG, SWOT dan Benchmarking pada Perusahaan Rubby Hijab. Universitas Suryakancana. 